\title{
Subspecific differentiation in male reproductive traits and virgin queen preferences, in Bombus terrestris
}

\author{
Thomas LeCocQ ${ }^{1}$, Audrey CopPÉE ${ }^{1}$, Tiffany Mathy ${ }^{1}$, Patrick Lhomme ${ }^{2}$, \\ Marie-Claire CAMMAERTS-Tricot ${ }^{3}$, Klara UrbanOVÁ $^{4}$, Irena VAlterovÁ ${ }^{4}$, \\ Pierre RASMONT ${ }^{1}$
}

\footnotetext{
${ }^{1}$ Research institute of Biosciences, Laboratory of Zoology, University of Mons, Place du Parc 20, 7000, Mons, Belgium ${ }^{2}$ Department of Plant Protection Biology, Division of Chemical Ecology, Swedish University of Agricultural Sciences, Alnarp, Sweden

${ }^{3}$ Université Libre de Bruxelles, Evolutionary Biology and Ecology, av. FD Roosevelt 50, 1050, Brussels, Belgium

${ }^{4}$ Institute of Organic Chemistry and Biochemistry, Academy of Sciences of the Czech Republic, Flemingovo nám. 2,166 10, Prague, Czech Republic
}

Received 29 July 2014 - Revised 11 December 2014 - Accepted 12 January 2015

\begin{abstract}
Many species display local variations in pre-mating signals and in mating preferences. This may lead to discrimination against potential foreign mates that may ultimately lead to reproductive isolation. However, the extent to which population differentiation in mating cues affects the species recognition has received little empirical support. Here, we investigate the consequence of geographic differentiation in male reproductive traits on female preferences to these traits in Bombus terrestris. We characterise (1) the geographic differentiation in male cephalic labial gland secretions (CLGS), a key trait for mate attraction, and (2) the preference of virgin females to the CLGS of different subspecies. Our results show geographic CLGS differences parallel with divergences in female preferences for these secretions. This geographic CLGS differentiation in males, along with female preference for sympatric males, could lead to or reflect a pre-mating isolation among subspecies.
\end{abstract}

\section{mate preference / reproductive traits / cephalic labial gland secretions / subspecies / olfactometer}

\section{INTRODUCTION}

Pre-mating communication is of particular interest for evolutionary biologists. Indeed, premating signals and reproductive traits play a key role in the maintenance of reproductive isolations (Paterson 1993; Grant and Grant 1996). These

Electronic supplementary material The online version of this article (doi:10.1007/s13592-015-0349-y) contains supplementary material, which is available to authorized users.

Corresponding author: T. Lecocq, thomas.lecocq@umons.ac.be; I. Valterová,irena@uochb.cas.cz Manuscript editor: James Nieh Thomas Lecocq and Audrey Coppée contributed equally to this work. signals and traits are under strong selection for maximizing encounter rates among conspecific mates (Andersson 1994; Wyatt 2003) and minimizing hybridization events among syntopicrelated species (Loftus-Hills and Littlejohn 1992; Symonds et al. 2009). This leads to speciesspecific pre-mating signals (Paterson 1993; Symonds et al. 2009). Among widespread species, local variations of pre-mating signals and reproductive traits may occur (Förschler and Kalko 2007; Blyth et al. 2008) in response to local changes in factors that affect communication systems, such as genomes (e.g. genetic drift and/or genetic differentiation fostered by a low gene flow between populations), intraspecific interactions or interspecific interactions (reviewed in Lecocq et al. 2013b). These local divergences in mating signals, that parallel divergences in mating 
preferences, can lead to discrimination against foreign partners (Andersson 1994; Ptacek 2000; Nosil et al. 2007). Ultimately, this may lead to reproductive isolation and speciation (Andersson 1994; Ptacek 2000; Nosil et al. 2007). However, the extent to which population differentiation in mating cues affects species recognition has received little empirical support (Andersson 1994; Vereecken et al. 2007; Lecocq et al. 2013a).

Many bumblebee species are widely distributed and occur in a broad range of habitats and species communities and different habitats (Williams 2007). Moreover, bumblebee species have been affected by biogeographic events (Williams et al. 2011; Duennes et al. 2012; Lecocq et al. 2013a; 2013b). These features of bumblebees could lead to intraspecific spatial genetic differentiation (Avise 2000) as well as to spatially varying selection regimes within species (Wright 1951) and, consequently, to evolutionary divergences (Williams 1991; Estoup et al. 1996).

Like many other insect, the mate recognition of bumblebee species includes both behavioural and chemical features (Williams 1991; Baer 2003; Ayasse and Jarau 2014). Most bumblebee males patrol along paths along which they scent-mark objects with their cephalic labial gland secretions (CLGS) that attract conspecific virgin females (Bergström et al. 1981; Ayasse and Jarau 2014). The CLGS are species-specific complex mixtures (mainly aliphatic compounds) dominated by few compounds with a higher concentration (main components) (Calam 1969; Svensson 1979), produced de novo by cephalic labial glands (Žáček et al. 2013). CLGS locale variations have been observed among widespread bumblebee species (Terzo et al. 2005; Lecocq et al. 2013a), especially in Bombus terrestris (L.) (Coppée et al. 2008; Lecocq et al. 2013b). However, the consequences of this interspecific differentiation on the premating recognition remain mainly unknown (but see Ings et al. 2005).

Here, we assess the differentiation of male CLGS between $B$. terrestris populations by performing comparative chemical analyses prior to testing the hypothesis of population-specific preferences of $B$. terrestris virgin queens by performing bioassays on queens presented with population-specific CLGS blends. Specifically, we ask the following question: Do B. terrestris females have populations-specific odour preferences?

\section{MATERIALS AND METHODS}

\subsection{Studied species}

B. terrestris (L.), within which several subspecies are recognised, is one of the most widespread and abundant bumblebee species in the West Palaearctic region (Rasmont et al. 2008). In this study, we focused on four local populations corresponding to four allopatric subspecies (see origins in Table I): B. terrestris canariensis Pérez (Canary Islands), B. terrestris dalmatinus Dalla Torre (from South-Eastern France to Central Asia), B. terrestris sassaricus Tournier (Sardinia) and B. terrestris xanthopus Kriechbaumer (Corsica, Tuscan Archipelago). Previous studies have already detected a CLGS differentiation between the three last taxa (Coppée et al. 2008; Lecocq et al. 2013b; 2014). Nest searching queens of $B$. terrestris sassaricus and B. terrestris xanthopus collected in the wild are used for founding colonies in laboratory following Lhomme et al. (2013). Nests of B. terrestris canariensis and $B$. terrestris dalmatinus were provided by Biobest bvba (Westerlo, Belgium). We maintained nests in a wooden box in a controlled climate dark room at $29^{\circ} \mathrm{C}$ and $55-65 \%$ relative humidity (RH) and fed ad libitum with Salix pollen and sugar syrup (Lhomme et al. 2012; Lhomme et al. 2013). We also used Bombus ignitus Smith (China, Korea and Japan) provided by Biobest, an allopatric sister species of $B$. terrestris, as an interspecific control (Table I). All males were killed by freezing. We used 5- to 15-day-old males when the $B$. terrestris males are the most attractive to females (Coppée et al. 2011).

\subsection{Analyses of cephalic labial gland secretions}

We extracted the CLGS of male $B$. terrestris $(n=46)$ and B. ignitus $(n=12)$ in $400 \mu \mathrm{L} n$-hexane (De Meulemeester et al. 2011) (Table I). We preserved all CLGS extracts at $-40{ }^{\circ} \mathrm{C}$ until analyses. We quantified and qualified the CLGS composition by gas chromatography-mass spectrometry (GC/MS) on a Finigan GCQ equipped with a DB-5 ms non-polar capillary 
Table I. Table of sampling.

\begin{tabular}{llclll}
\hline Taxa & Sex & N spec. & Location & Latitude & Longitude \\
\hline B. terrestris dalmatinus & Female & 50 & Rhodos (Greece) & $36^{\circ} 11^{\prime} \mathrm{N}$ & $27^{\circ} 55^{\prime} \mathrm{E}$ \\
B. terrestris dalmatinus & Male & 10 & Rhodos (Greece) & $36^{\circ} 11^{\prime} \mathrm{N}$ & $27^{\circ} 55^{\prime} \mathrm{E}$ \\
B. terrestris canariensis & Male & 12 & Canary Islands (Spain), Tenerife & $28^{\circ} 27^{\prime} \mathrm{N}$ & $16^{\circ} 23^{\prime} \mathrm{W}$ \\
B. terrestris sassaricus & Male & 12 & Sardinia (Italy), Monte Padru & $41^{\circ} 01^{\prime} \mathrm{N}$ & $9^{\circ} 12^{\prime} \mathrm{E}$ \\
B. terrestris xanthopus & Male & 12 & Corsica (France) & $42^{\circ} 17^{\prime} \mathrm{N}$ & $8^{\circ} 52^{\prime} \mathrm{E}$ \\
B. ignitus & Male & 12 & Japan & $36^{\circ} \mathrm{N}$ & $138^{\circ} \mathrm{E}$ \\
\hline
\end{tabular}

column (5\% phenyl (methyl) polysiloxane stationary phase; $30 \mathrm{~m} \times 0.25 \mathrm{~mm} \times 0.25 \mu \mathrm{m}$ ) and an ion trap instrument working in electron ionisation mode "full scan (300-600)". We used a splitless injection mode $\left(220^{\circ} \mathrm{C}\right)$ and helium as carrier gas $(50 \mathrm{~cm} / \mathrm{s})$. The temperature programme of the column was set to $70{ }^{\circ} \mathrm{C}$ for $2 \mathrm{~min}$ and then increased at a rate of $10{ }^{\circ} \mathrm{C} / \mathrm{min}$ to $320{ }^{\circ} \mathrm{C}$. The temperature was then held at $320{ }^{\circ} \mathrm{C}$ for $5 \mathrm{~min}$. We identified compounds in Xcalibur ${ }^{\mathrm{TM}}$ using their mass spectra compared to those at the National Institute of Standards and Technology library (NIST, USA) using NIST MS Search 2.0. We quantified the peak areas of compounds with automatic peak detection and noise measurement. We calculated relative amounts (RA in \%) of compounds in each sample by dividing the peak areas of compounds by the total area of compounds in each sample. We did not use any correction factor to calculate the RA of individual compounds. We elaborated the data matrix for each species with the relative proportion of each compound for each individual using GCAligner 1.0 (Dellicour and Lecocq 2013) (Table S1).

We performed statistical comparative analyses of the CLGS in R program (R Development Core Team 2013) in order to assess the CLGS differentiations between populations. We compared the complete profile (all compounds are taken into account) for each sample (ungrouped) with non-metric multidimensional scaling (nMDS) ordination using a Bray-Curtis similarity matrix, three dimensions and 50 runs (R-package ecodist; Goslee and Urban 2007). When we detected CLGS differentiations between population groups in nMDS, we assessed results by performing permutation-based version of the multivariate analysis of variance (perMANOVA) using the Bray-Curtis similarity matrix and 10,000 permutations (R-package vegan; Oksanen et al. 2011). Like conventional analyses of variances, the perMANOVA calculates an $F$ statistic by taking the ratio of among group sums of squares to within group sums of squares. The perMANOVA is robust to violations of multivariate normality. When we tested more than two groups and the returned $P$ value was significant $(P<0.01)$, multiple pairwise comparisons were conducted and $P$ values were adjusted using Bonferroni's correction to avoid increases of type I error due to multiple testing.

We determined compounds that are specific and regular to each group detected in nMDS and perMANOVA (indicator compounds) using the indicator value (IndVal) method (Dufrêne and Legendre 1997). The value given is the product of relative abundance and relative frequency of occurrence of a compound within a group. We evaluated the statistical significance of a compound as an indicator at the 0.01 level with a randomization procedure.

\subsection{Bioassays-attractiveness/arresting effect of males' head extracts}

In bioassays, we used 1- to 2-week-old virgin queens of $B$. terrestris dalmatinus (queens of other subspecies were not available) $(n=50$; Table I) from different four colonies (Table S2) provided by Biobest bvba (Westerlo, Belgium) (strain from Rhodes, Greece). We maintained virgin queens in a wooden box in a controlled climate dark room at $29^{\circ} \mathrm{C}$ and $55-65 \%$ relative humidity (RH) and fed ad libitum with Salix pollen and sugar syrup (Lhomme et al. 2012; Lhomme et al. 2013).

We performed the behavioural tests in an olfactometer made of a glass tray $(70 \times 70 \times 8 \mathrm{~cm})$ covered with a polycarbonate plate (Coppée et al. 2011). A circular iron wire 1-mm mesh was placed in the centre to avoid direct 
contact between the virgin queens and the secretions (i.e. only the volatile compounds were perceptible by the virgin queens; see Coppée et al. 2011). The arena was divided into four square areas $(35 \times 35 \mathrm{~cm})$, each corner contained, respectively, (1) a blank filter paper, (2) filter paper with $2.5 \mu \mathrm{L}$ hexane, (3) filter paper with $2.5 \mu \mathrm{L}$ of the CLGS extract of a male from " $\mathrm{X}$ " origin (one male equivalent) and (4) filter paper with $2.5 \mu \mathrm{L}$ of the CLGS extract of a male from "Y" origin (Figure 1a). The position of each type of these filter papers was randomly chosen for each bioassay. Each filter paper (hexane, blank filter, $\mathrm{X}$ origin, and Y origin) is renewed for each bioassay. We performed the following pairwise comparisons between the CLGS extract of each subspecies: (1) CLGS of B. terrestris dalmatinus versus CLGS of $B$. terrestris dalmatinus, (2) CLGS of B. terrestris dalmatinus versus CLGS of $B$. terrestris canariensis, (3) CLGS of B. terrestris dalmatinus versus CLGS of $B$. terrestris sassaricus, (4) CLGS of B. terrestris dalmatinus versus CLGS of $B$. terrestris xanthopus and (5) CLGS of $B$. terrestris dalmatinus versus CLGS of $B$. ignitus . Each kind of pairwise comparisons was tested ten times, each time with a CLGS extract of a different male and each time with a different queen. The required CLGS extracts are randomly chosen among the 10 (B. terrestris dalmatinus) or the 12 (other subspecies) male CLGS extracts. The required 10 queens are randomly chosen among our $50 \mathrm{~B}$. terrestris dalmatinus queens. The queens used for one kind of CLGS comparisons were not used for the other ones.

A digital camera (Philips SPC 900 NC PC Camera) connected to a computer was set centred above the experimental arena, allowing the recording of female movement. The room was kept at $20-30{ }^{\circ} \mathrm{C}$ and $45-55 \% \mathrm{RH}$. The tests were done in red light to avoid the influence of daylight on the behaviour. Exposed to daylight, queens walked endlessly around the arena.

The following protocol was used. A virgin female was placed in a Petri dish $(9.2 \mathrm{~cm}$ in diameter) and set free after 1-2 min when the virgin female calmed down. Ten seconds after the female was free, her position was recorded every $5 \mathrm{~s}$, during $5 \mathrm{~min}$ (i.e. 60 successive positions of each tested queen, see Table S2). After each test, the entire olfactometer was cleaned using an odourless soap (Panama ${ }^{\circledR}$ ) and acetone.

To test whether the number of females approaches were dependent on the odour source (four different filter papers of two controls and two male extracts), each of the pairwise comparisons (B. terrestris dalmatinus versus $B$. terrestris dalmatinus, $B$. terrestris dalmatinus versus $B$. terrestris canariensis, $B$. terrestris dalmatinus versus $B$. terrestris sassaricus, $B$. terrestris dalmatinus versus $B$. terrestris xanthopus and $B$. terrestris dalmatinus versus $B$. ignitus) was tested by performing a generalised linear model with a Poisson distribution (GLM, Poisson error, log link function), using an ANOVA and chi-square test as test criterion. Post hoc pairwise comparisons were made using Tukey contrasts (R-package multicomp; Hothorn et al. 2008).

\section{RESULTS}

\subsection{CLGS extract comparison}

Ninety-two compounds were detected in the CLGS of $B$. terrestris (Table S1). The main compounds in the different $B$. terrestris subspecies were (1) dihydrofarnesol (B. terrestris canariensis), (2) dihydrofarnesol + tricosane + icos-17-enal + hexadecenyl hexadecenoate $(B$. terrestris xanthopus), (3) dihydrofarnesol (B. terrestris dalmatius) and (4) dihydrofarnesol (B. terrestris sassaricus). By main compounds, we mean compounds that have the highest relative amount at least in one individual of the taxa. The main compounds of B. ignitus were octadec-11-enol and dihydrofarnesol. Compositions of the head extracts of $B$. ignitus, $B$. terrestris dalmatinus, $B$. terrestris xanthopus and $B$. terrestris sassaricus were similar to previous studies (Coppée et al. 2008; De Meulemeester et al. 2011; Lecocq et al. $2013 \mathrm{~b})$. The composition of $B$. terrestris canariensis CLGS was here reported for the first time.

The nMDS assessed that the CLGS compositions of $B$. terrestris dalmatinus, $B$. terrestris canariensis, $B$. terrestris sassaricus, $B$. terrestris xanthopus and B. ignitus were different from one another (Figure 2). The global perMANOVA results confirm these interspecific differentiations (global perMANOVA: $\mathrm{DF}=4$, $F=45.47, P$ value $<0.01): B$. terrestris dalmatinus versus $B$. terrestris canariensis 
A
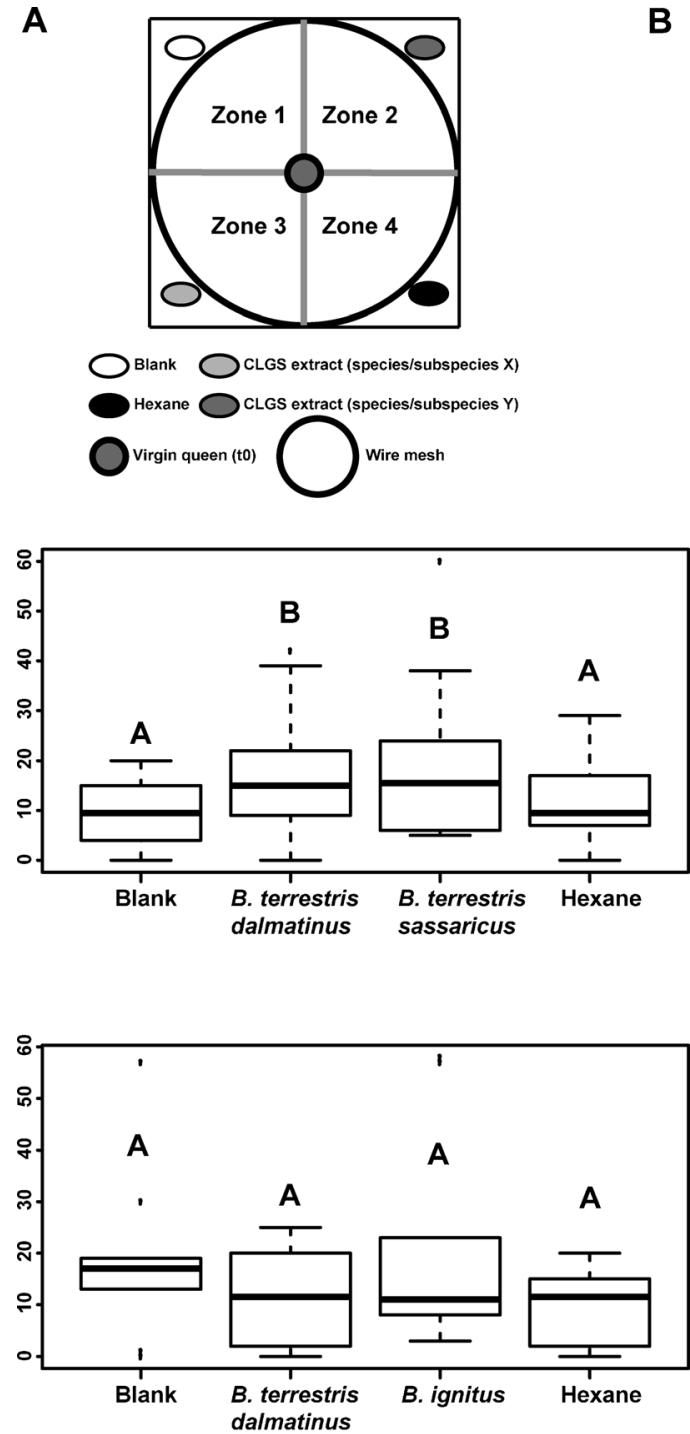

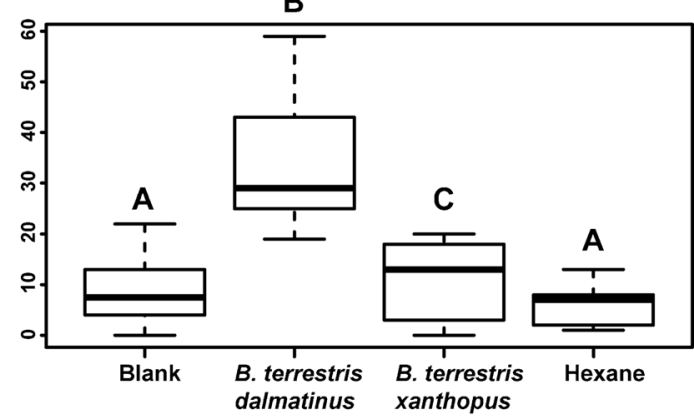

B

B

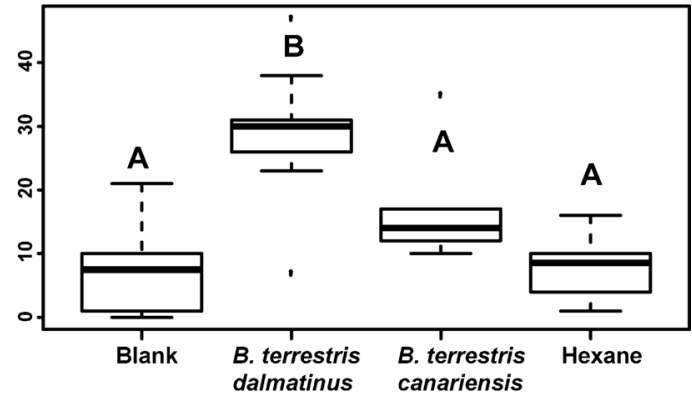

B

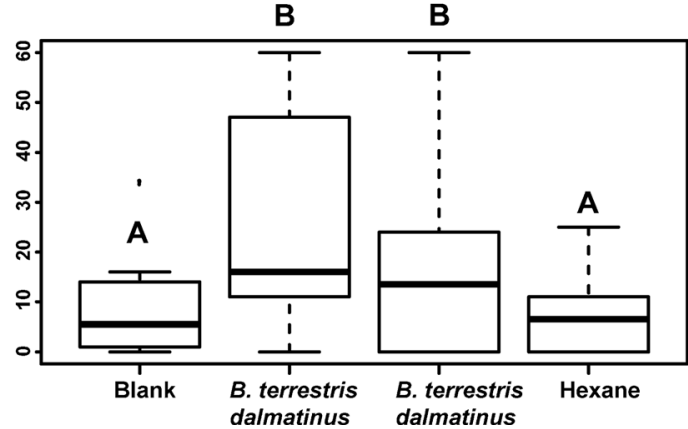

Figure 1. Experimental apparatus and bioassays results. a Experimental apparatus: in the low left corner, a consubspecific male head extract was set; in the high right corner, a non-consubspecific male head extract was set. b Presence (the position of the queen in the experimental apparatus every $5 \mathrm{~s}$ ) of B.t. dalmatinus virgin queens in each area of the olfactometer, containing blank, hexane, and two different extracts of cephalic labial gland secretions. The axis y is the sum of observation of each queen in a particular area of the olfactometer when its position is recorded every $5 \mathrm{~s}$ during $5 \mathrm{~min}$; total observation per queen is 60 .

perMANOVA: $\mathrm{DF}=1, F=24.34, P$ value $<0.01$; $B$. terrestris dalmatinus versus $B$. terrestris sassaricus perMANOVA: $\mathrm{DF}=1, F=29.63, \quad P$ value $<0.01 ; B$. terrestris dalmatinus versus $B$. terrestris xanthopus perMANOVA: $\mathrm{DF}=1$, $F=33.74, P$ value $<0.01 ; B$. terrestris dalmatinus versus $B$. ignitus perMANOVA: $\mathrm{DF}=1$, $F=52.98, P$ value $<0.01 ; B$. terrestris xanthopus versus $B$. terrestris canariensis perMANOVA: $\mathrm{DF}=1, F=35.70, P$ value $<0.01 ; B$. terrestris xanthopus versus $B$. terrestris sassaricus perMANOVA: $\mathrm{DF}=1, F=44.69, P$ value $<0.01$; 


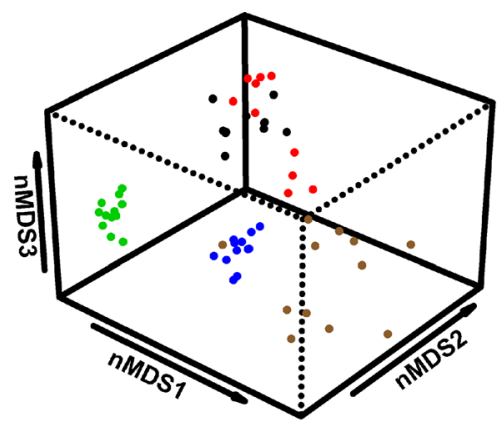

B. ter. canariensis

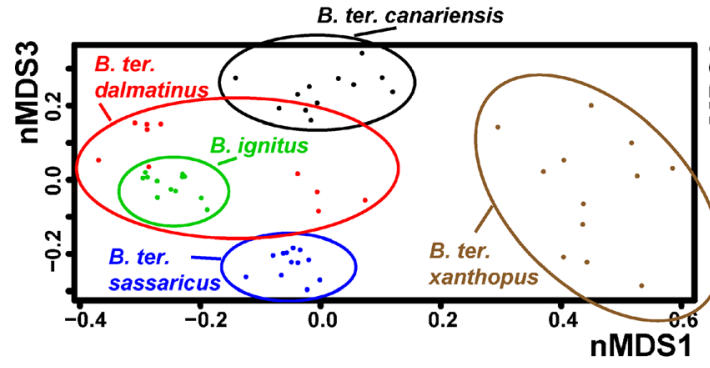

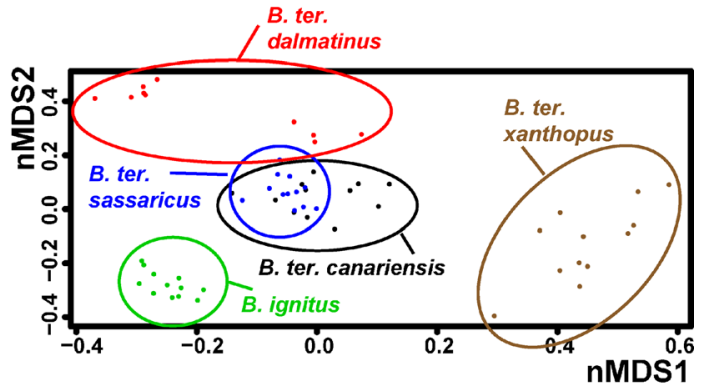

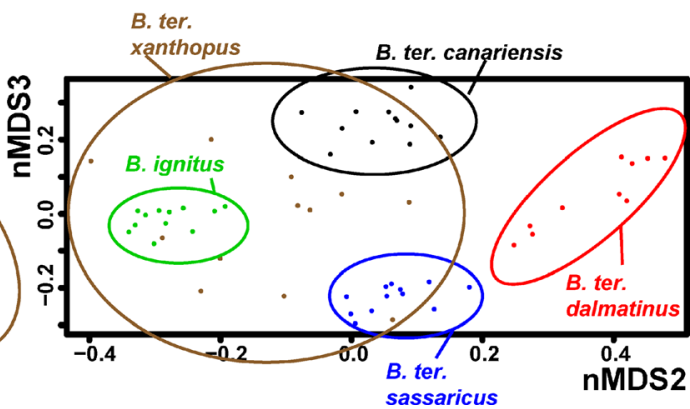

Figure 2. CLGS statistical analysis results. Non-metric multidimensional scaling (nMDS) ordination using a BrayCurtis similarity matrix based on the cephalic labial gland secretions of $B$. terrestris subspecies and $B$. ignitus (stress value $=0.13, R^{2}=0.92$ ). The nMDS1, nMDS2 and nMDS3 are first, second and third axes of the nMDS. Ellipses represent significant groups detected by the permutation-based version of the multivariate analysis of variance using the Bray-Curtis similarity matrix.

B. terrestris xanthopus versus $B$. terrestris ignitus perMANOVA: $\mathrm{DF}=1, F=62.37, P$ value $<0.01$; $B$. terrestris canariensis versus $B$. terrestris sassaricus perMANOVA: $\mathrm{DF}=1, F=50.23, P$ value $<0.01 ; B$. terrestris canariensis versus $B$. terrestris ignitus perMANOVA: $\mathrm{DF}=1$, $F=93.27, P$ value $<0.01$; and $B$. terrestris sassaricus versus $B$. terrestris ignitus perMANOVA: $\mathrm{DF}=1, F=154.01, P$ value $<0.01$. The IndVal method revealed several significant and strong indicator compounds (IndVal $>0.70$ ) including main compound (B. ignitus and B. terrestris xanthopus) or at least compounds with a large relative abundance (B. terrestris canariensis) in each group except for $B$. terrestris dalmatinus and B. terrestris sassaricus (Table S1).

\subsection{Bioassays — subspecific preferences}

In bioassays, we always found differences between the treatments (GLM, Poisson; $P$ value $<0.01)$ except for the pairwise comparison between CLGS of $B$. terrestris dalmatinus versus $B$. ignitus (GLM, Poisson; $P$ value $=0.16)$ (Table S3).

Virgin queens always preferred the CLGS extract to blank or pure solvent except for $B$. canariensis secretion (Figure 1b, Table II). Our results showed that $B$. terrestris dalmatinus females were statistically more attracted by the consubspecific CLGS blends when exposed to $B$. terrestris xanthopus and B. terrestris canariensis (Figure 1b, Table II). In contrast, there was no preference between consubspecific and non-consubspecific odour when the queen was exposed to $B$. terrestris sassaricus (Figure 1b, Table II).

When exposed to B. ignitus CLGS, the $B$. terrestris dalmatinus females reacted abnormally: they walked endlessly and erratically around the arena, exhibited stress behaviour (they reacted by getting excited, buzzing and walking very quickly), instead of exploring the arena and 
stopping near one odour source as they did with conspecific extracts.

\section{DISCUSSION}

\subsection{Subspecific differentiations of cephalic labial gland secretions and their consequences}

The interspecific comparison between $B$. ignitus and B. terrestris subspecies indicate an expected CLGS divergence (as observed by De Meulemeester et al. 2011) as observed in other interspecific comparisons in bumblebee species (Calam 1969; Terzo et al. 2005). Between B. terrestris subspecies, our comparative analyses show that all $B$. terrestris subspecies have specific CLGS, as previously observed for all taxa except B. terrestris canariensis (these results are congruent with previous studies; Coppée et al. 2008; Lecocq et al. 2013b). According to the allopatric distribution of studied $B$. terrestris subspecies, the observed CLGS differentiations were most likely driven by a persistent lack of gene flow between them (see Estoup et al. 1996; Lecocq et al. $2013 b$ ), possibly reinforced by the preference of local females for sympatric males as previously suggested in insular bumblebees (see Lecocq et al. 2013b). Such a differentiation of reproductive traits may directly interfere with the pre-mating communication between differentiated populations as observed in many organisms (Andersson 1994; Kawazu et al. 2005). However, the differentiation consequences are poorly predictable without bioassays since they can lead to simple regional variation without reproductive isolation (i.e. dialects consisting of different relative amounts of the same key compounds; Tòth et al. 1992; Vereecken et al. 2007) or to the establishment of a reproductive isolation barrier between populations (Martens 1996).

Our bioassays clearly show the consequence of an interspecific differentiation: B. terrestris dalmatinus queens display behaviour that we 
interpreted as stressed (see Section 3) resulting in non-significant biased results when they are exposed to B. ignitus CLGS. We hypothesise that this behaviour could reflect a defensive behaviour (see Lhomme et al. 2012; Lhomme et al. 2013) resulting from the extensive divergence of B. ignitus CLGS. Indeed, B. ignitus secretions could be interpreted as the chemical signature of an intruder or as a repellent by $B$. terrestris dalmatinus queens as observed in other bioassays where different species face each other (e.g. Lhomme et al. 2012).

Inside $B$. terrestris, our bioassays show that the CLGS differentiation of $B$. terrestris canariensis and B. terrestris xanthopus (large differentiation with taxon-specific strong indicator compounds and taxons-pecific compounds with a large relative abundance) leads to $B$. terrestris dalmatinus queens discriminating against foreign mates. This is in accordance with previous bioassays on mating choices which show preferences of commercially imported $B$. terrestris dalmatinus queens for consubspecific males in the UK (Ings et al. 2005). Moreover, many studies on sexual selection have largely documented that individuals often recognize and prefer to mate with individuals from "local" rather than "exotic" populations (Andersson 1994; Boake 2002 but in contrast see Vereecken et al. 2007). Since previous studies (de Jonghe 1986; Estoup et al. 1996; Rasmont and Adamski 1996; Rasmont et al. 2008) have detected significant genetical and ecological differentiation between $B$. terrestris canariensis, B. terrestris xanthopus and B. terrestris dalmatinus or even have suggested speciation processes within B. terrestris (Lecocq et al. 2013b; 2014), the observed CLGS differentiation and our bioassays results could reflect a pre-mating isolation through this male chemical reproductive trait.

In contrast to other studied B. terrestris taxa, the CLGS divergence (but without strong indicator compounds or changes in compounds with a large relative abundance) between $B$. terrestris dalmatinus and $B$. terrestris sassaricus does not lead to a discrimination of $B$. terrestris dalmatinus queens against $B$. terrestris sassaricus CLGS in bioassays. Even if the components of the CLGS that constitute the pheromones are not known (i.e. those components that release a female response or convey information for females), we speculate that the CLGS of $B$. terrestris sassaricus are considered as similar to consubspecific male secretions for $B$. terrestris dalmatinus queens (i.e. no change in compounds that allow the pre-mating recognition). This rules out the hypothesis of a pre-mating isolation between these two taxa through a CLGS differentiation and reinforces the conspecificity suggested by other studies (Lecocq et al. 2013b; 2014).

The significant $B$. terrestris dalmatinus female preferences for the CLGS of its own subspecies compared to those of some subspecies in laboratory do not necessarily result in pre-mating isolation in the wild. Establishing pre-mating isolation would require testing all four subspecies for their pre-mating isolation from one another (i.e. ring species may occur) using mating trials that would be difficult to conduct. Therefore, the present more feasible bioassays should be extended to all taxa included in B. terrestris and coupled with other evidence (i.e. integrative taxonomy; Lecocq et al. 2011; 2014) and possibly other reproductive traits to conclude to pre-mating isolation.

\subsection{Implications for B. terrestris dalmatinus invasions}

In the last decades, B. terrestris, especially $B$. terrestris dalmatinus, has become increasingly important commercially for its pollination services to agriculture (Velthuis and van Doorn 2006). However, as B. terrestris easily naturalizes (Buttermore et al. 1998; Goulson and Hanley 2004), the commercial trade in $B$. terrestris has led to it becoming invasive in several regions as result of deliberate introductions or accidental escapes (Torretta et al. 2006; Velthuis and van Doorn 2006). The main consequences of these invasions are (1) competition for floral and nesting resources with local species/ subspecies (Kanbe et al. 2008; Nagamitsu et al. 2009); (2) the transmission of parasites and pathogens to local subspecies due to parasitosis found in commercial colonies (Colla et al. 2006; Meeus et al. 2011; Murray et al. 2013); and (3) the dilution of 
characters (genetic, morphologic and ethologic) between native and non-native commercially transported subspecies or loss of reproductive fitness (Kanbe et al. 2008; Yoon et al. 2009).

Although a hybridization between $B$. terrestris subspecies in laboratory conditions has been demonstrated (de Jonghe 1986; Ings et al. 2005), the appearance of wild hybrids remains a rare event (Rasmont and Adamski 1996; Rasmont and Quaranta 1997; Quaranta and Felicioli 2012). This corresponds with our behavioural results showing that $B$. terrestris dalmatinus queens significantly prefer their own subspecies rather than subspecies with significantly differentiated CLGS (B. terrestris canariensis and B. terrestris xanthopus). In contrast, $B$. terrestris dalmatinus queens do not significantly prefer the consubspecific CLGS in comparison with subspecies with very similar CLGS (B. terrestris sassaricus). This suggests that the consequences of introductions or accidental escapes of $B$. terrestris dalmatinus in the natural range of other $B$. terrestris subspecies may vary according to the native subspecies. We speculate that an intersubspecific dilution of characters between non-native $B$. terrestris dalmatinus and native $B$. terrestris canariensis/B. terrestris xanthopus is unlikely because of their different CLGS and their partially differentiated ecological features (Rasmont et al. 2008; Lecocq et al. 2013b; 2014). Besides the transmission of parasites and pathogens, the main consequence of a B. terrestris dalmatinus invasion in Corsica and in the Canary Islands could thus be the competition for floral and nesting resources between taxa. In contrast, $B$. terrestris dalmatinus introductions in Sardinia could lead to dilution of characters with native B. terrestris sassaricus according to the lower differentiation between the two taxa. However, since we tested only the queen of $B$. terrestris dalmatinus, we do not know if the queens of other $B$. terrestris taxa display also preferences for "local" rather than "exotic" males (i.e. asymmetrical species isolation). Therefore, more studies on natural intersubspecific hybridizations are needed to check these hypotheses.

\section{ACKNOWLEDGMENTS}

We thank R. De Jonghe, J. Vermeulen, N. E. Raine, L. Chittka and Biobest bvba for providing the biological material. We are grateful to T. Ings for his comments and discussions and for help with the English. We would like to thank the "Fonds de la Recherche Fondamentale et Collective" (Project 2.4.564.06 F), the Czech Science Foundation (grant No. 14-04291S) and the "Fonds pour la formation à la Recherchedans l'Industrie et dans l'Agriculture", which awarded a grant to TL, AC and PL. TL is post-doc in the context of the BELBEES project funded by the Belgian Scientific Politic (BELSPO, BR/132/A1/BELBEES).

Différenciation subspécifique dans les traits reproductifs des mâles et les préférences des reines vierges, chez Bombus terrestris

Préférence pour un partenaire / comportement reproducteur / sécrétions / glande labiale céphalique / sous -espèce / olfactomètre

Innerartliche Differenzierung in Merkmalen des Reproduktionstrakts von Männchen der Hummel Bombus terrestris und die Bevorzugung von unbegatteten Jungköniginnen

Paarungspräferenz / Reproduktionsmerkmale Sekrete der Kopflabialdrüsen / Unterart / Olfaktometer

\section{REFERENCES}

Andersson, M. (1994) Sexual selection. Princeton University Press, Princeton, USA

Avise, J.C. (2000) Phylogeography: The History and Formation of Species. Harvard University Press, Cambridge, MA

Ayasse, M., Jarau, S. (2014) Chemical ecology of bumble bees. Annu. Rev. Entomol. 59, 299-319

Baer, B. (2003) Bumblebees as model organisms to study male sexual selection in social insects. Behav. Ecol. Sociobiol. 54, 521-533

Bergström, G., Svensson, B.G., Appelgren, M., Groth, I. (1981) Complexity of bumble bee marking pheromones: biochemical, ecological and systematical interpretations. Syst. Assoc. special vol. 175-183

Blyth, J.E., Lachaise, D., Ritchie, M.G. (2008) Divergence in multiple courtship song traits between Drosophila santomea and D. yakuba. Ethology 114, 728-736 
Boake, C.R.B. (2002) Sexual signaling and speciation, a microevolutionary perspective. Genetica 116, 205214

Buttermore, R.E., Pomeroy, N., Hobson, W., Semmens, T., Hart, R. (1998) Assessment of the genetic base of Tasmanian bumble bees (Bombus terrestris ) for development as pollination agents. J. Apic. Res. 37, 23-25

Calam, D.H. (1969) Species and sex-specific compounds from the heads of male bumblebees (Bombus spp.). Nature 221, 856-857

Colla, S.R., Otterstatter, M.C., Gegear, R.J., Thomson, J.D. (2006) Plight of the bumble bee: Pathogen spillover from commercial to wild populations. Biol. Conserv. 129, $461-467$

Coppée, A., Terzo, M., Valterová, I., Rasmont, P. (2008) Intraspecific variation of the cephalic labial gland secretions in Bombus terrestris (L.) (Hymenoptera: Apidae). Chem. Biodivers. 5, 2654-2661

Coppée, A., Mathy, T., Cammaerts, M.-C., Verheggen, J.F., Terzo, M., Iserbyt, S., Valterová, I., Rasmont, P. (2011) Age-dependent attractivity of males' sexual pheromones in Bombus terrestris (L.) [Hymenoptera, Apidae]. Chemoecology 21, 75-82

de Jonghe, R. (1986) Crossing experiments with Bombus terrestris (LINNAEUS, 1758) and Bombus terrestris xanthopus KRICHBAUMER, 1870 and some notes on diapause and nosemose (Hymenoptera : Apoidea). Phegea 14, 19-23

De Meulemeester, T., Gerbaux, P., Boulvin, M., Coppée, A., Rasmont, P. (2011) A simplified protocol for bumble bee species identification by cephalic secretion analysis. Insectes Soc. 58, 227-236

Dellicour, S., Lecocq, T. (2013) GCALIGNER 1.0: an aligment program to compute a multiple sample comparison data matrix from large eco-chemical datasets obtained by gas chromatography. J. Sep. Sci. 36, 3206-3209

R Development Core Team (2013) R: A language and environment for statistical computing. R Foundation for Statistical Computing, Vienna, Austria

Duennes, M.A., Lozier, J.D., Hines, H.M., Cameron, S.A. (2012) Geographical patterns of genetic divergence in the widespread Mesoamerican bumble bee Bombus ephippiatus (Hymenoptera: Apidae). Mol. Phylogenet. Evol. 64, 219-231

Dufrêne, M., Legendre, P. (1997) Species assemblages and indicator species: The need for a flexible asymmetrical approach. Ecol. Monogr. 67, 345-366

Estoup, A., Solignac, M., Cornuet, J.-M., Goudet, J., Scholl, A. (1996) Genetic differentiation of continental and island populations of Bombus terrestris (Hymenoptera: Apidae) in Europe. Mol. Ecol. 5, 19-31

Förschler, M.I., Kalko, E.K.V. (2007) Geographical differentiation, acoustic adaptation and species boundaries in mainland citril finches and insular Corsican finches, superspecies Carduelis citrinella. J. Biogeogr. 34, 1591-1600
Goslee, S.C., Urban, D.L. (2007) The ecodist package for dissimilarity-based analysis of ecological data. J. Stat. Softw. 22, 1-19

Goulson, D., Hanley, M.E. (2004) Distribution and forage use of exotic bumblebees in South Island, New Zealand. N. Z. J. Ecol. 28, 225-232

Grant, B.R., Grant, P.R. (1996) Cultural inheritance of song and its role in the evolution of Darwin's finches. Evolution 50, 2471-2487

Hothorn, T., Bretz, F., Westfall, P. (2008) Simultaneous inference in general parametric models. Biom. J. 50, 346-63

Ings, T.C., Raine, N.E., Chittka, L. (2005) Mating preference in the commercially imported bumblebee species Bombus terrestris in Britain (Hymenoptera: Apidae). Entomol. Gen. 28, 233-238

Kanbe, Y., Okada, I., Yoneda, M., Goka, K., Tsuchida, K. (2008) Interspecific mating of the introduced bumblebee Bombus terrestris and the native Japanese bumblebee Bombus hypocrita sapporoensis results in inviable hybrids. Naturwissenschaften 95, 1003-1008

Kawazu, K., Suzuki, Y., Yoshiyasu, Y., Castillon, E.B., Ono, H., et al. (2005) Attraction of Cnaphalocrocis medinalis (Lepidoptera: Crambidae) males in Southeast Asia to female sex pheromone traps: Field tests in southernmost China, northern Vietnam and southern Philippines with three synthetic pheromone blends regarding geographic. Appl. Entomol. Zool. 40, 483488

Lecocq, T., Lhomme, P., Michez, D., Dellicour, S., Valterová, I., Rasmont, P. (2011) Molecular and chemical characters to evaluate species status of two cuckoo bumblebees: Bombus barbutellus and Bombus maxillosus (Hymenoptera, Apidae, Bombini). Syst. Entomol. 36, 453-469

Lecocq, T., Dellicour, S., Michez, D., Lhomme, P., Vanderplanck, M., Valterová, I., Rasplus, J.-Y., Rasmont, P. (2013a) Scent of a break-up: phylogeography and reproductive trait divergences in the red-tailed bumblebee (Bombus lapidarius). BMC Evol. Biol. 13, 263

Lecocq, T., Vereecken, N.J., Michez, D., Dellicour, S., Lhomme, P., Valterová, I., Rasplus, J.-Y., Rasmont, P. (2013b) Patterns of genetic and reproductive traits differentiation in mainland vs. Corsican populations of bumblebees. PLoS One 8, e65642

Lecocq, T., Brasero, N., De Meulemeester, T., Michez, D., Dellicour, S., Lhomme, P., de Jonghe, R., Valterová, I., Urbanová, K., Rasmont, P. (2014) An integrative taxonomic approach to assess the status of Corsican bumblebees: implications for conservation. Anim. Conserv. doi:10.1111/acv.12164

Lhomme, P., Ayasse, M., Valterová, I., Lecocq, T., Rasmont, P. (2012) Born in an alien nest: how do social parasite male offspring escape from host aggression? PLoS One 7, e43053

Lhomme, P., Sramkova, A., Kreuter, K., Lecocq, T., Rasmont, P. (2013) A method for year-round rearing of cuckoo bumblebees (Hymenoptera : Apoidea : 
Bombus subgenus Psithyrus). Ann. Soc. Entomol. Fr. 49, 37-41

Loftus-Hills, J.J., Littlejohn, M.J. (1992) Reinforcement and reproductive character displacement in Gastrophryne carolinensis and G. olivacea (Anura: Microhylidae): a reexamination. Evolution 46, 896906

Martens, J. (1996) Vocalizations and speciation of Palearctic birds. In: Kroodsma, D.E., Miller, E.H. (eds) Ecol. Evol. Acoust. Commun. Birds. Comstock Publishing, Ithaca (NY), pp 221-240

Meeus, I., Brown, M.J.F., De Graaf, D.C., Smagghe, G. (2011) Effects of Invasive Parasites on Bumble Bee Declines. Conserv. Biol. 25, 662-671

Murray, T.E., Coffey, M.F., Kehoe, E., Horgan, F.G. (2013) Pathogen prevalence in commercially reared bumble bees and evidence of spillover in conspecific populations. Biol. Conserv. 159, 269-276

Nagamitsu, T., Yamagishi, H., Kenta, T., Inari, N., Kato, E. (2009) Competitive effects of the exotic Bombus terrestris on native bumble bees revealed by a field removal experiment. Popul. Ecol. 52, 123-136

Nosil, P., Crespi, B.J., Gries, R., Gries, G. (2007) Natural selection and divergence in mate preference during speciation. Genetica 129, 309-327

Oksanen, F.J., Blanchet, G., Kindt, R., Legendre, P., O’Hara, R.G., Simpson, G.L., Solymos, P., Stevens, M.H.H., Wagner, H. (2011) Vegan: Community Ecology Package. http:/cran.r-project.org/web/packages/ vegan/

Paterson, H.E.H. (1993) Evolution and the recognition concept of species. The Johns Hopkins University Press

Ptacek, M.B. (2000) The role of mating preferences in shaping interspecific divergence in mating signals in vertebrates. Behav. Processes 51, 111-134

Quaranta, M., Felicioli, A. (2012) First report of Bombus terrestris xanthopus Kriechbaumer on the Italian peninsula (Hymenoptera: Apidae). Ann. Soc. Entomol. Fr. 48, 343-346

Rasmont, P., Adamski, A. (1996) Les Bourdons de la Corse (Hymenoptera, Apoidea, Bombinae). Notes fauniques de Gembloux 31, 1-87

Rasmont, P., Quaranta, M. (1997) I Bombi dell'Arcipelago Toscano (Hymenoptera Apidae). Boll. Soc. Entom. Ital. 129, 31-38

Rasmont, P., Coppée, A., Michez, D., De Meulemeester, T. (2008) An overview of the Bombus terrestris (L. 1758) subspecies (Hymenoptera: Apidae). Ann. Soc. Entomol. Fr. 44, 243-250

Svensson, B.G. (1979) Pyrobombus lapponicus auct., in Europe recognized as two species: P. lapponicus (Fabricius, 1793) and P. monticola (Smith, 1849)
(Hymenoptera, Apoidea, Bombinae). Insect Syst. Evol. 10, 275-296

Symonds, M.R.E., Moussalli, A., Elgar, M.A. (2009) The evolution of sex pheromones in an ecologically diverse genus of flies. Biol. J. Linn. Soc. 97, 594-603

Terzo, M., Urbanová, K., Valterová, I., Rasmont, P. (2005) Intra and interspecific variability of the cephalic labial glands' secretions in male bumblebees: the case of Bombus (Thoracobombus) ruderarius and $B$. (Thoracobombus) sylvarum Hymenoptera, Apidae. Apidologie 36, 85-96

Torretta, J.P., Medan, D., Arahamovich, A.H. (2006) First record of the invasive bumblebee Bombus terrestris (L.) (Hymenoptera, Apidae) in Argentina. Trans. Am. Entomol. Soc. 132, 285-289

Tòth, M., Löfstedt, C., Blair, B.W., Cabello, T., Farag, A.I., et al. (1992) Attraction of male turnip moths Agrotis segetum (Lepidoptera: Noctuidae) to sex pheromone components and their mixtures at 11 sites in Europe, Asia, and Africa. J. Chem. Ecol. 18, 1337-1347

Velthuis, H.H.W., van Doorn, A. (2006) A century of advances in bumblebee domestication and the economic and environmental aspects of its commercialization for pollination. Apidologie 37, 421-451

Vereecken, N.J., Mant, J., Schiestl, F.P. (2007) Population differentiation in female sex pheromone and male preferences in a solitary bee. Behav. Ecol. Sociobiol. 61, $811-821$

Williams, P.H. (1991) The bumble bees of the Kashmir Himalaya (Hymenoptera: Apidae, Bombini). Bull. Nat. Hist. Museum 60, 1-204

Williams, P.H. (2007) The distribution of bumblebee colour patterns worldwide: Possible significance for thermoregulation, crypsis, and warning mimicry. Biol. J. Linn. Soc. 92, 97-118

Williams, P.H., An, J., Huang, J. (2011) The bumblebees of the subgenus Subterraneobombus: Integrating evidence from morphology and DNA barcodes (Hymenoptera, Apidae, Bombus). Zool. J. Linn. Soc. 163, 813-862

Wright, S. (1951) The genetical structure of populations. Ann. Eugen. 15, 323-354

Wyatt, T.D. (2003) Pheromones and animal behaviour: communication by smell and taste. Cambridge University Press, Cambridge, UK

Yoon, H.J., Sohn, M.R., Choo, Y.M., Li, J., Sohn, H.D., Jin, B.R. (2009) Defensin gene sequences of three different bumblebees, Bombus spp. J. Asia. Pac. Entomol. 12, 27-31

Žáček, P., Prchalová-Hornákov, D., Tykva, R., Kindl, J., Vogel, H., Svatoš, A., Pichová, I., Valterová, I. (2013) De novo biosynthesis of sexual pheromone in the labial gland of bumblebee males. ChemBioChem 14, 361-371 